\title{
Sıçan Böbrek Dokusunda Bakırın Neden Olduğu Oksidatif Stres ve DNA Hasarlarına Karşı Astaksantinin Etkisi
}

\author{
Aydın Şükrü BENGÜ ${ }^{*}$, H. Turan AKKOYUN², Mahire BAYRAMOGLU AKKOYUN³ \\ Mehmet Sait IZGG ${ }^{4}$ \\ ${ }^{1}$ Bingöl Universitesi, Bingöl Üniversitesi Să̆llk Hizmetleri MYO, Bingöl, 12000, Bingöl, Türkiye \\ ${ }^{2}$ Siirt Universitesi, Veteriner Fakültesi, Fizyoloji ABD, 56100, Siirt, Türkiye \\ ${ }^{3}$ Siirt Universitesi, Veteriner Fakültesi,, Biyokimya ABD,56100, Siirt, Türkiye \\ ${ }^{4}$ Siirt Üniversitesi, Mühendislik Fakültesi, Kimya Mühendsiliği, 56100, Siirt, Türkiye \\ (ORCID:0000-0002-7635-4855) (ORCID: 0000-0002-4547-8003) \\ (ORCID:0000-0001-5150-5402) (ORCID:0000-0003-3685-3219)
}

\begin{abstract}
$\ddot{\mathbf{O} z}$
Sıçan böbrek dokusunda bakır $\left(\mathrm{Cu}^{+2}\right)$ ile oluşturulan oksidatif stres ve DNA hasarlarına karşı astaksantin'in (AST) koruyucu özelliği araştırıldı. 28 adet yetişkin wistar albino cinsi sıçan dört gruba ayrıldı. Kontrol grubu:\% $0.9 \mathrm{NaCl}$ intraperitoneal (i.p.), Bakır grubu $3 \mathrm{mg} \mathrm{kg}$ (i.p.) $\mathrm{Cu}^{+2}$, Astaksantin grubu $100 \mathrm{mg} \mathrm{kg}^{-1} \mathrm{AST}$ (oral), Bakır+Astaksantin grubu: $3 \mathrm{mg} \mathrm{kg}$ (i.p.) $+100 \mathrm{mg} \mathrm{kg}^{-1}$ AST (oral) uygulandı. 3. günün sonunda sıçanların böbrek dokuları alındı. Böbrek homojenatlarında önemli antioksidan enzimlerden SOD, CAT, GPx aktiviteleri ve 8-hidroksi-2' -deoksiguanozin (8-OHdG) düzeyi değerlendirildi. SOD aktivitesinin bakır uygulanan grupta ve bakır+AST uygulanan grupta kontrole oranla azaldığı( $\mathrm{p}<0.05)$, gözlemlendi. GPx enzim aktivitesi ise bakır $(p<0.001)$ uygulanan ve bakır+AST $(p<0.01)$ uygulanan gruplarda kontrole göre azaldı ğ belirlendi. CAT aktivitesi, kontrol grubuna kıyasla bakır uygulanan grupta düşmenin $(\mathrm{p}<0.001)$ olduğu tesbit edildi. 8-OHdG düzeyinde; kontrole oranla bakır+AST grubunda anlamlı bir artış $(\mathrm{p}<0.001)$ belirlendi. Çalışma sonucunda elde edilen bulguların bu alanda yapılacak olan farklı çalışmalara kaynak olabileceği düşünülmektedir.
\end{abstract}

Anahtar kelimeler: Astaksantin, Böbrek, Bakır, DNA hasarı.

\section{Effect of astaxanthin against oxidative stress and DNA damage caused by copper in rat kidney tissue}

\begin{abstract}
The protective properties of astaxanthin (AST) against copper $\left(\mathrm{Cu}^{+2}\right)$ oxidative stress and DNA damage in rat kidney tissue were investigated. 28 adult wistar albino rats were divided into four groups. Control group: $0.9 \%$ $\mathrm{NaCl}$ intraperitoneal (ip), Copper group: $3 \mathrm{mg} \mathrm{kg}^{-1}$ (ip) $\mathrm{Cu}+2$, Astaxanthin group: $100 \mathrm{mg} \mathrm{kg}^{-1}$ AST (oral), Copper + Astaxanthin group: $3 \mathrm{mg} \mathrm{kg}^{-1}$ (ip) + $100 \mathrm{mg} \mathrm{kg}^{-1}$ AST (oral) was administered. At the end of day 3 , kidney tissues of the rats were taken. SOD, CAT, GPx activities and 8-hydroxy-2 '-deoxyguanosine (8-OHdG) levels which are important antioxidant enzymes in kidney homogenates were evaluated. SOD activity was reduce observed in the copper treated group and copper + AST group compared to control ( $\mathrm{p}<0.05)$. GPx enzyme activity was found to be decreased according to the control in the group treated with copper $(\mathrm{p}<0.001)$ and copper + AST $(\mathrm{p}<0.01)$. CAT activity was decreased in the copper treated group compared to the control group ( $\mathrm{p}<0.001)$. At 8-OHdG level; a significant increase in copper + AST group $(\mathrm{p}<0.001)$ was determined compared to control. As a result of the study, it is thought that the findings can be a source for different studies to be done in this field.
\end{abstract}

Keywords: Astaxanthin, Kidney, Copper, DNA damage.

\footnotetext{
*Sorumlu yazar: abengu@bingol.edu.tr Geliş Tarihi: 09/03/2019, Kabul Tarihi: 11/07/2019
} 


\section{Giriş}

$\operatorname{Bakır}\left(\mathrm{Cu}^{+2}\right)$; bir çok hücresel enzimin fizyolojik fonksiyonunu yerine getirebilmesi için gerekli eser elementlerden biridir [1]. Bu nedenle vücutta demir ve çinkodan sonra en fazla bulunan eser elementtir [2]. Bakır, mitokondri kaynaklı enerji üretiminde etkili olmanın yanı sıra, demir homeostazisi, serbest radikallerin detoksifikasyonu, kollojen ve elastinin çapraz bağ oluşturması, nörotransmitter sentezi gibi hücre fizyolojisi için önemli olan birçok enzimin kimyasında da rol alan katalitik bir kofaktördür [1]. Bakır insan metabolizmasında biyokatalizör olarak birçok görevde rol alan önemli temel elementlerden biridir. Bakır, demir emilimi ve hemoglobin sentezi için gereklidir [3]. Bakır eksikliğine bağlı olarak insanda epilepsi, MS (Multipl Skleroz), deri ve saçlarda depigmantasyon görülmektedir. Fazla alınan bakır vücut için toksiktir. Fazla miktarda alınan bakır, vücuttaki bazı enzimlerin çalışmasını engeller. Aynı zamanda mukoza iltihaplanması, damar, karaciğer ve böbrek hastalıkları, depresyonla seyreden merkezi sinir sistemi irritasyonları görülebilir [4]. Bakır gibi geçiş metalleri reaktif oksijen türleri (ROS) üretimini önemli ölçüde arttırır. DNA, oksidatif hasar görmesi muhtemel moleküllerden biridir. Urasil, timin glikoller, 8-oksoadenin, 8-oksoguanin ve 5formamidpridin, bir ROS radikal saldırısından sonra DNA bozunmasının ürünleridir [5]. Vücutta en çok bakır içeren dokular; karaciğer, kalp, böbrek ve beyindir [2]. Karotenoidler, esas olarak bitkilerde bulunan yağda çözünen doğal pigment sınıfıdır. Kimyasal yapıları ve biyolojik etkileşimleri sebebiyle potansiyel antioksidan özelliklere sahiptirler. Diyette bol miktarda bulunan karotenoidler; $\beta$-karoten, likopen, lutein, $\beta$-kriptoksantin, zeaksantin ve astaksantindir (AST) [6]. Ksantofil karotenoid olan AST, kimyasal olarak 3,3'-dihidroksi- $\beta, \beta$ '-karoten-4,4'-dion olarak tanımlanır[7]. Aynı zamanda AST, deneysel çalışmalarında ortaya çıkan güçlü antioksidan ve anti-apoptoz etkileri olan denizsel kaynaklı, bir ksantofilkarotenoiddir [8]. AST, mikroalg Haematococcus pluvialis'ten elde edilir [9]. AST, antiinflamatuar, antikanser ve kardiyoprotektif aktiviteler gibi çok çeşitli fizyolojik ve farmakolojik aktivitelere sahiptir [10-11]. Yapılan bir çalışmada astaksantinin çeşitli böbrek hastalıkları üzerinde önleyici bir etkisi olduğunu kantlamıştır [8]. Son y1llarda 8-hidroksi-2'-deoksiguanozin (8-OHdG) oksidasyonu ve DNA mutasyonları ile ilgili yapılan çalışmalar çok ilgi görmüştür. Bu sebeple çalışmada; bakırın neden olduğu sıçan böbrek dokusunda oksidatif stres ve DNA hasarına karşı astaksantinin etkisinin araştırılması amaçlanmıştır.

\section{Materyal ve Metot}

Çalışmanın deneysel prosedürleri Bingöl Üniversitesi Hayvan Deneyleri Yerel Etik Kurul Komitesi tarafindan(BUHADEK:4.10.2018-2018/08-08/02) onaylandı. Çalışmada 200-300 g ağırlığa sahip 28 adet yetişkin Wistar albino erkek sıçan kullanıldı. Siçanlar $20 \pm 2{ }^{\circ} \mathrm{C}$ sıcaklık ve onikişer $(12 \mathrm{~h})$ saatlik aydınlık-karanlık siklusu sağlanan odada, kafeslerde muhafaza edilerek beslenmeleri sağlandı. Ortama uyumları sağlandıktan sonra sıçanlar randomize olacak şekilde 4 gruba ayrıldı. Kontrol grubu: \% 0.9 $\mathrm{NaCl}$ intraperitoneal (i.p.) uyguland. Bakır $\left(\mathrm{Cu}^{+2}\right)$ grubu: $\mathrm{Cu}^{+2} 3 \mathrm{mg} / \mathrm{kg}$ (i.p) enjekte edildi [12]. Astaksantin (AST) grubu: $100 \mathrm{mg} / \mathrm{kg}$ AST (oral) uyguland1 [13]. Bakır $\left(\mathrm{Cu}^{+2}\right)+$ Astaksantin (AST) grubu $\mathrm{Cu}^{+2} 3 \mathrm{mg} / \mathrm{kg}$ (i.p) ile $100 \mathrm{mg} / \mathrm{kg}$ AST (oral) uyguland. 3.günün sonunda sıçanlar $\left(60 \mathrm{mg} \mathrm{kg}^{-1}\right.$ Ketaminehidroklorit+10 mg kg${ }^{-1}$ dozunda Xylazinehidroklorit) ile anestezi altına alınarak böbrek doku örnekleri alındı. Alınan doku örnekleri analizlerin yapılacağı zamana kadar $-80^{\circ} \mathrm{C}$ de muhafaza edildi.

\subsection{Doku Örneklerinin Hazırlanması ve Enzim Aktivite Ölçümü}

0.5 gr tartılarak alınan böbrek doku örneklerinin üzerine $5 \mathrm{~mL} \mathrm{pH}$ değeri 7.4 olan tampondan eklendikten sonra bir homojenizatör yardımı ile parçalandı. Ardından ultrasonik homojenizatör kullanılarak daha ileri bir parçalanmaya tabi tutulan doku numuneleri soğutmalı santrifüj kullanılarak $30 \mathrm{dk}$ boyunca santrifüjlendi. Elde edilen süpernatantlar ependorf tüplerine aktarilarak enzim aktivite ölçümleri için hazır hale getirildi. Çalı̧̧mada enzim aktivite ölçümleri spektrofotometrik olarak gerçekleştirildi. Süperoksit dismutaz (SOD) enzim aktivite ölçümü $560 \mathrm{~nm}$ dalga boyunda [14], Glutatyon peroksidaz (GPx) enzim aktivite ölçümü $340 \mathrm{~nm}$ dalga boyunda [15], son olarak Katalaz (CAT) enzimi aktivite ölçümü $240 \mathrm{~nm}$ dalga boyunda [16] belirlenen absorbans değişimlerine dayanılarak tesbit edildi. Protein miktarının belirlenmesinde ise Bradford [17] metodu kullanıldı. 


\subsection{8-hidroksi-2-deoksiguanozin (8-OHdG) Düzeyinin Ölçümü}

Böbrek doku örneklerinde 8-hidroksi-2-deoksiguanozin (8-OHdG) düzeyleri ticari ELISA kiti (SunRed DZE-201110032) kullanılarak belirlendi [18].

\section{3. İstatistiksel Değerlendirme}

Çalışmada istatistiksel analizler, SPSS yazılımı, Windows 20.0 sürümü kullanılarak hesaplandı. Sonuçlar ortalama \pm standart sapma olarak verildi. Gruplar arasındaki farklılıkları belirlemede ANOVA ve Tukey çoklu karşılaştırma testi kullanıldı.

\section{Bulgular ve Tartışma}

DNA hasar1, kodlama özelliklerini değiştiren çoğaltma veya transkripsiyon gibi metabolizmay1 engelleyen, DNA'nın yapısındaki herhangi bir modifikasyondur [19]. Oksidatif stres, reaktif oksijen türlerinin (ROS) konsantrasyonları ile antioksidan savunma mekanizmaları arasındaki dengesizliği belirtmek için yaygın olarak kullanılan bir terimdir [20]. ROS, biyolojik sistemlerde çok yüksek bir reaktivite ve dolayısıyla yüksek toksisite ile karakterize edilir. Özellikle çoklu doymamış yağ asitleri, fonksiyonel ve yapısal proteinleri ve lipitleri oksitleyebilirler [21]. Hücre içi ROS tarafindan üretilen oksidatif hasar, DNA baz modifikasyonlarına, tek ve çift sarmal kırılmalarına ve çoğu toksik veya mutajenik olan apurinik/apirimidinik lezyonların oluşmasına neden olur. Bu nedenle, ROS sadece hastalık durumlarının etiyolojisine dâhil edilmekle kalmaz, ayrıca ortaya çıkan DNA hasarı da zararlı biyolojik sonuçlara doğrudan katkıda bulunabilir [22]. Hücre içi reaktif oksijen türlerinin (ROS) ürettiği en yaygın lezyon 8-hidroksideoksi guanozindir (8-OHdG). Bu lezyon G:C'den T'ye: mutasyonlara neden olur ve yüksek oranda mutajenik olarak kabul edilir [23]. Antioksidan, enzimler sıklıkla oksidatif stresin belirteçleri olarak kullanılır ve bu biyobelirteçler arasında, süperoksit dismutaz (SOD), glutatyonperoksidaz (GPx) ve katalaz (CAT), normal hücre fonksiyonu için homeostazın korunmasında önemlidir [24]. SOD, peroksit anyon radikallerini temizleyen ve serbest radikallere bağlı olarak lipit peroksidasyonunu engelleyen önemli bir enzimdir [25]. Bu nedenle SOD'un etkisi, hücrelerin ve dokuların biyolojik bütünlügünü, süperoksit serbest radikalinin zararlı etkilerine karşı korumaktır [26]. SOD hücreleri oksidatif strese karşı koruyan serbest radikal temizleyici enzimdir [27]. Çalışmamızda SOD enzim aktivitesinin (Şekil I) kontrol grubuna oranla bakır uygulanan grupta ve bakır+AST uygulanan grupta önemli düzeyde azaldığı $(p<0.05)$, bakır uygulamas1 yapılan grubuna oranla AST uygulamas1 yapılan grupta ise enzim aktivite düzeyinde artışın $(\mathrm{p}<0.01)$ olduğu belirlendi. AST grubu ile kıyaslandığında $\mathrm{Cu}+$ AST uygulaması yapılan grupta SOD enzim aktivitesindeki azalışın anlamlı olduğu tespit edildi $(\mathrm{p}<0.001)$.

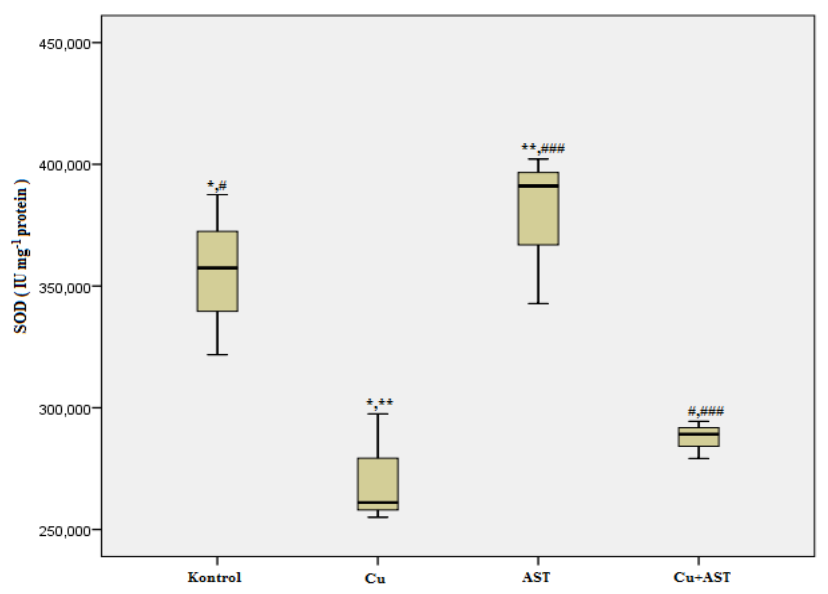

Şekil 1. Böbrek doku Süperoksit dismutaz_aktivitesi $* * \mathrm{p}<0.01, *, \# \mathrm{p}<0.05,{ }^{\# \# \#} \mathrm{p}<0.001$ 
Siçanlarda civa klorürün neden olduğu oksidatif stres ve böbrek fonksiyon bozukluğu üzerine astaksantinin etkisiyle ilgili yapılan bir çalışmada biyokimyasal parametrelerden SOD aktivitesi değerlendirildiğinde, kontrol grubuna göre kiyaslandığında civaklorür uygulanan grupta enzim aktivitesinde düşmenin olduğunu tespit etmişlerdir [28]. Bu kapsamda yapılan başka bir çalışmada, akut böbrek yaralanmasına üzerine astaksantinin etkisi değerlendirilmiş ve böbrek yaralanması üzerine astaksantinin iyileştirici etkisi olduğunu belirtmişlerdir [29]. Glutatyonperoksidaz (GPx) hücrelerde oluşan hidroperoksitlerin uzaklaştırılmasından sorumlu sitozolik bir enzimdir [30]. Çalışmamızda GPx, enzim aktivite düzeyleri incelendiğinde ise; (Şekil 2) kontrol grubuna oranla bakır $(p<0.001)$ ve bakır+AST $(\mathrm{p}<0.01)$ uygulanan gruplarda düşme tesbit edildi. AST uygulaması yapılan grup bakır uygulanan grup ile kıyaslandığında bakır grubunda GPx enzim aktivitesinin azaldığı belirlendi $(\mathrm{p}<0.05)$.

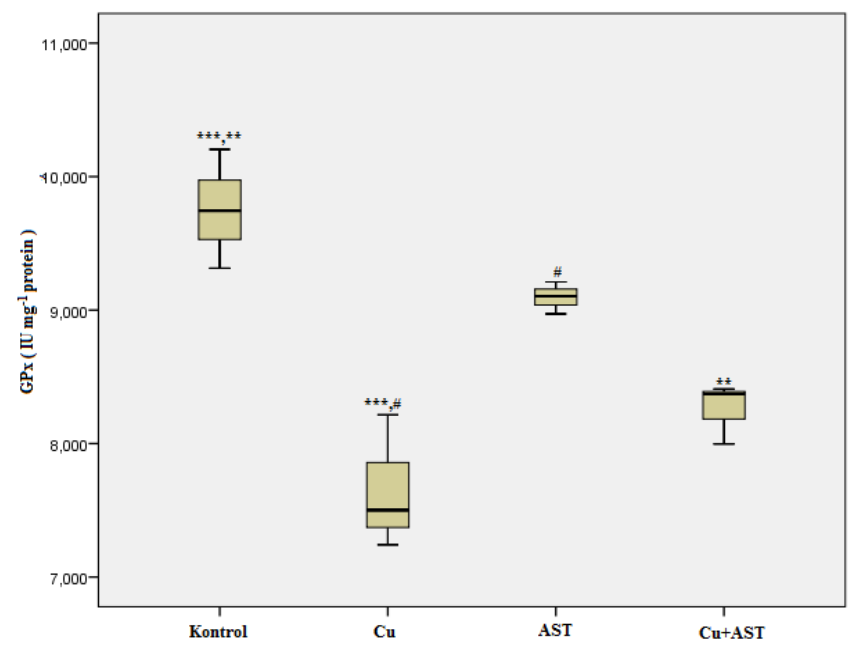

Şekil 2. Böbrek dokusu Glutatyon peroksidaz aktivitesi $* * *, \mathrm{p}<0.001, * *, \mathrm{p}<0.01,{ }^{\#} \mathrm{p}<0.05$

Sıçanlarda astaksantinin (AST), akut böbrek hasarı (CI-AKI) üzerindeki koruyucu etkisini ve SIRT1-p53 yolu ile astaksantin arasındaki ilişkiyi araştırmak için yapılan çalışmada biyokimyasal parametrelerden GSH-Px değerlendirilmiş AST uygulmasının enzim aktivitesi üzerine olumlu etkisinin olduğu tespit edilmiştir [31]. Sıçanlarda cıva klorürün neden olduğu oksidatif stres ve böbrek fonksiyon bozukluğu üzerine astaksantinin etkisiyle ilgili yapılan çalışmada biyokimyasal parametrelerden GSH-Px değerlendirildiğinde, kontrol grubuna göre kıyaslandığında civaklorür uygulanan grupta düşmenin olduğunu tespit etmişlerdir [28]. Katalaz (CAT) serbest radikal birikimini ve lipit peroksidasyonunu önleyen önemli enzimler arasındadır [25]. Çalışmada önemli antioksidan enzimler içerisinde yer alan CAT enzim aktivite düzeyi incelendi (Şekil 3). Bakır uygulanan grupta CAT enzim aktivitesinin kontrole kıyasla azaldığ 1 tesbit edildi $(\mathrm{p}<0.001)$. Yine kontrole oranla bakır+AST uygulanan gruptaki azalmanın anlamlı olduğu görüldü $(\mathrm{p}<0.01)$. Bakır grubuna oranla AST grubunda istatistiksel olarak anlamlı bir artışı olduğu $(\mathrm{p}<0.001)$, AST grubuna oranla $\mathrm{Cu}+\mathrm{AST}$ grubunda azalmanın olduğu tesbit edildi $(\mathrm{p}<0.01)$ Yapılan bir çalışmada arsenik ile oluşturulan böbrek hasarına karşı astaksantinin koruyucu etkisi olduğu ve yine bu çalışmada biyokimyasal parametrelerden CAT değerlendirildiğinde kontrol grubuna oranla arsenik uygulanan grupta enzim aktivitesinde anlamlı azalma olduğu gözlenmiştir [32]. 


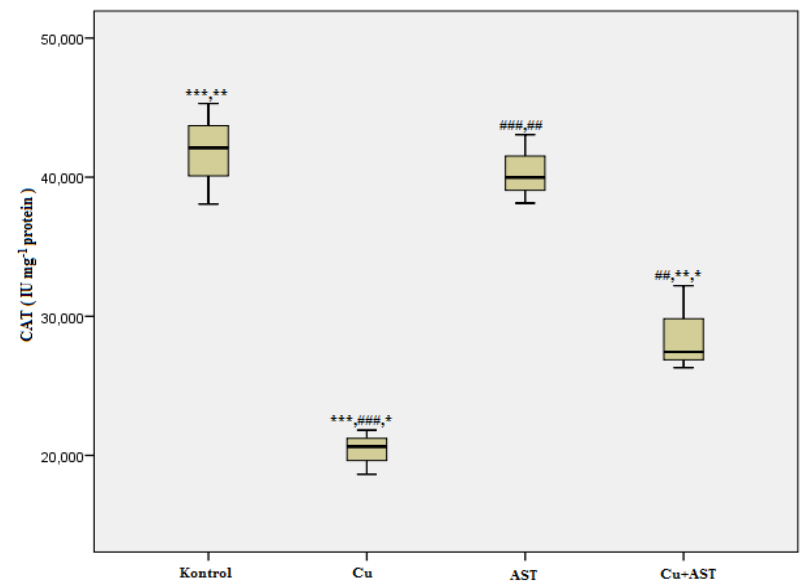

Şekil 3. Böbrek dokusu Katalaz aktivitesi $* \mathrm{p}<0.05, * *, \# \mathrm{p}<0.01, * * *, \# \# \mathrm{p}<0.001$

8-Hidroksiguanin (8-OH-Gua), Escherichia coli ve memeli hücrelerinde esas olarak GC $\rightarrow$ TA transversiyonlarını indükleyen başlıca oksidatif DNA hasarı formudur [33-35]. Çalışmada, bakıra maruz kalan sıçanların böbreğinde, kontrole oranla 8-OHdG düzeyinde istatistiksel olarak anlamlı bir artış $(\mathrm{p}<0.001)$ belirlendi. Aynı zamada kontrole oranla bakır+AST grubunda anlamlı bir artma görüldü ( $\mathrm{p}<0.001)$ (Şekil 4). Bu kapsamda böbrek 8-OHdG düzeyinde hasarına neden olan arsenik üzerine astaksantinin koruyucu etkisi ile ilgili yapılan bir çalışmada kontrol grubuna oranla arsenik uygulanan grupta artmanın olduğu gözlenmiştir [32].

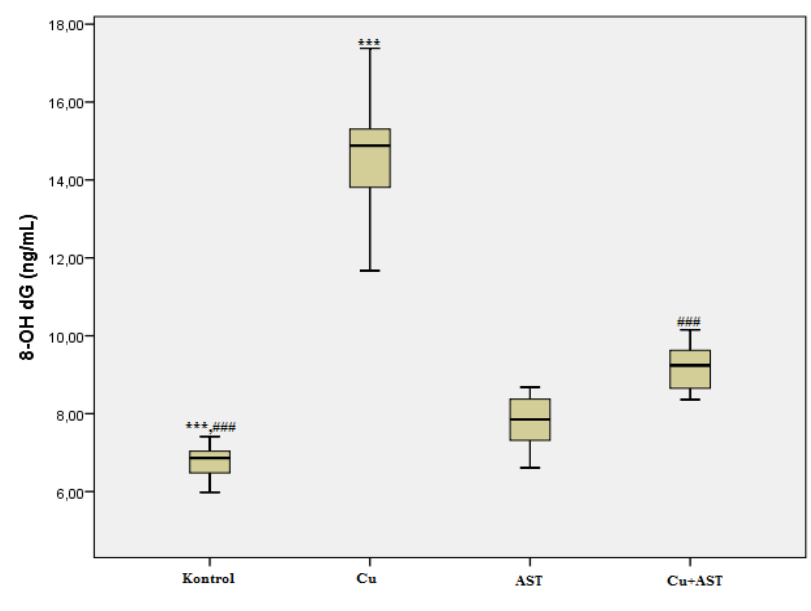

Şekil 4. Böbrek doku 8-OHdG düzeyi $(* * *, \# \#$ p $<0.001)$ şeklinde gösterildi.

\section{Sonuç ve Öneriler}

Çalışmada elde edilen sonuçlara dayanılarak; oksidatif stres başta olmak üzere, antioksidan metabolizmada önemli yeri olan bakır uygulaması ile azalan enzim aktivitelerinin, astaksantin uygulamasından olumlu yönde etkilendiği söylenebilir. Antioksidan enzim aktivitelerindeki bu olumlu etki, DNA hasarının inhibisyonu ile desteklenmiştir. Çalışma sonucunda elde edilen bulguların bu alanda yapılacak olan farklı çalışmalara kaynak olabileceği düşünülmektedir.

\section{Teşekkür}

Çalışmamızda yardımlarını esirgemeyen Bingöl Üniversitesi Merkezi Laboratuvar Uygulama ve Araştırma Merkezinin idareci ve çalışanlarına teşekkür ederiz. 


\section{Kaynaklar}

[1] Kabak Y.B., Gülbahar M.Y. 2013. Siçanlarda deneysel bakır zehirlenmesinde karaciğer ve böbrek dokularında apoptozisin belirlenmesi. Ankara Üniversitesi Veteriner Fakültesi Dergisi, 60: 39-45.

[2] Turgut S., Ercan M., Turgut G., Zencir M., Genç O. 2000. Yüksek bakır ile çinkonun böbrek ve kalp üzerine etkileri. Süleyman Demirel Üniversitesi Tıp Fakültesi Dergisi,7 (3): 35-42.

[3] Akarsu T. 2013. Tokat ili Bölgesi Eser Elementleri (selenyum, çinko, bakır) Referans Aralıkları. Selçuk Üniversitesi, Sağlık Bilimleri Entitüsü, Yüksek Lisans Tezi, 21s, Konya.

[4] Güneş Ö.N. 2014. Hellp Sendromlu Hastalarda Serum Çinko Ve Bakır Düzeyleri. Atatürk Üniversitesi, Sağlık Bilimleri Enstitüsü, Yüksek Lisans Tezi, 41s, Erzurum.

[5] Cervantes-Cervantes M.P. Calderón-Salinas J.V., Albores A., Muñoz-Sánchez J.L. 2005. Copper Increases the Damage to DNA and Proteins Caused by Reactive Oxygen Species. Biological Trace Element Research, 103 (3): 229-248.

[6] Turkez H., Geyikoglu F., Yousef M.I. 2013. Beneficial Effect of Astaxanthin on 2, 3, 7, 8tetrachlorodi benzo-p-dioxin-induced Liver Injury in Rats. Toxicology and Industrial Health, 29 (7): 591-599.

[7] Ekpe L., Inaku K., Ekpe V. 2018.Antioxidant Effects of Astaxanthin in Various Diseases-a Review. Journal of Molecular Pathophysiology, 7 (1): 1-6.

[8] Gao D., Li W. 2018. Research Progress of Astaxanthin on Contrast Agent Induced Acute Kidney Injury. Journal Cardiol and Cardiovasc Sciences, 2 (3): 6-9.

[9] Akca G., Eren H., Tumkaya L., Mercantepe T., Horsanali M.O., Deveci E., Yilmaz A. 2018. The Protective effect of Astaxanthin against Cisplatin-induced Nephrotoxicity in Rats. Biomedicine\&Pharmacotherapy, 100: 575-582.

[10] Akkoyun H.T., Bengü A.Ş., Ulucan A., Akkoyun Bayramoglu M., Ekin S., Temel Y., Çiftci M. 2018. Effect of Astaxanthin on Rat Brains Against Oxidative Stress Induced By Cadmium:Biochemical. Histopathological Evaluation, 8 (4): 33-39.

[11] Zhou L., Gao M., Xiao Z., Zhang J., Li X., Wang A. 2015. ProtectiveEffect of Astaxanthin Against Multiple Organ Injury in a Rat Model of Sepsis. Journal of Surgical Research, 195 (2): 559-567.

[12] Irato P., Santon A., Ossi E., Albergoni V. 2001. Interactions between Metals in Rat Liver and Kidney: Localization of Metallothionein. The Histochemical Journal, 33 (2): 79-86.

[13] Ohno M., Darwish W.S., Miki W., Ikenaka Y., Ishizuka M. 2011. Astaxanthin can Alter CYP1A-dependent Activities via Two Different Mechanisms: Induction of Protein Expression and Inhibition of NADPH P450 Reductase Dependent Electron Transfer. Food and ChemicalToxicology, (6): 1285-1291.

[14] Sun Yi., Oberley L.W., Ying Li. 1988. A Simple Method for Clinical Assay of Superoxide Dismutase. Clinical Chemistry, 3413: 497-500.

[15] Donald E.P., Valentina W.N. 1967. Studies on the Quantitative Characterization of Erythrocyte Glutathione Peroxidase. Journal of Laboratory and Clinical Medicine, (70): 158-169.

[16] Aebi H. 1984. Catalase in Vitro Assay Methods. Methods Enzymology, 105: 121-126.

[17] Bradford M.M. 1976. AR rapid and Sensitive Method for the Quantation of Microgram Quantaties of Protein Utiliging the Principle of Protein-Dye. Binding Analytical Biochemistry,72: 248.

[18] Özyurt H., Çevik Ö., Özgen Z., Özden A.S., Çadırcı S., Elmas M.A., Şener G. 2014. Quercetin protects radiation-induced DNA damage and apoptosis in kidney and bladder tissues of rats. Free radical research, 48 (10): 1247-1255.

[19] Gonzalez-Hunt C.P., Wadhwa M., Sanders L.H. 2018. DNA Damage by Oxidative Stress: Measurement Strategies for Two Genomes. Current Opinion in Toxicology, 7: 87-94.

[20] Sanda A., Gal A., Pintea A., Bedecean I., Arion A., Baba A.I. 2008. Influence of Astaxanthin Administration on Hepatic Oxidative Stress Markers in Rats Injected with Methylnitrosurea. Bulletin UASVM, 65: 1.

[21] Gałażyn-Sidorczuk M., Brzóska M.M., Jurczuk M., Moniuszko-Jakoniuk J. 2009. Oxidative Damage to Proteins and DNA in Rats Exposed to Cadmium and/or Ethanol. ChemicoBiological Interactions, 180 (1): 31-38. 
[22] Salmon T.B., Evert B.A., Song B., Doetsch P.W. 2004. Biological Consequences of Oxidative Stress-Induced DNA Damage in Saccharomycescerevisiae. Nucleic Acids Research, 32 (12): 3712-3723.

[23] Du W., Rani R., Sipple J., Schick J., Myers K.C., Mehta P., Pang Q. 2012. The FA Pathway Counteracts Oxidative Stress Through Selective Protection of Antioxidant Defense Gene Promoters. Blood, 119 (18): 4142-4151.

[24] Patlolla A.K., Barnes C., Yedjou C., Velma V.R., Tchounwou P.B. 2009. Oxidative Stress, DNA Damage, and Antioxidant Enzyme Activity Induced by Hexavalent Chromium in Sprague-DawleyRats. Environmental Toxicology: An International Journal, 24 (1): 66-73.

[25] Akkoyun H.T., Bengu A.S., Ulucan A , Bayramoglu-Akkoyun M., Arihan O. 2018. Protective Effect Of Ellagic Acid Against Carbon Tetrachloride (CCl4) Induced Oxidative Brain Injury In Rats. Fresenius Environmental Bulletin, 27 (5): 3148-3155.

[26] Otitoju O., Onwurah I.N., Otitoju G.T., Ugwu C.E. 2008. Oxidative Stress and Superoxide Dismutase Activity in Brain of Rats Fed with Diet Containing Permethrin. Biokemistri, 20 (2): 93-98.

[27] Elguindy N.M., Yacout G.A., El Azab E.F. 2018. Amelioration of DNA-Induced Oxidative Stress in Rat Kidney and Brain by the Essentialoil of Elettaria Cardamomum. Beni-Suef University Journal of Basic and Applied Sciences, 7 (3): 299-305.

[28] Augusti P.R., Conterato G.M.M., Somacal S., Sobieski R., Spohr P.R., Torres J.V., Emanuelli T. 2008. Effect of Astaxanthin on Kidney Function Impairment and Oxidative Stress Induced by Mercuric Chloride in Rats. Food and Chemical Toxicology, 46 (1): 212-219.

[29] Jing C., Wenhua L., Nana L., Yaren Y., Zheng D. 2015. Effect of Astaxanthin Intervention on Contrast-Induced Acute Kidney Injury in Experimental Rats. Chinese Journal of Nephrology, 31 (8): 604-609.

[30] Akkoyun H.T. 2012. Fötal Dönemde Nikotine Maruz Kalan Siçanlarda Oluşan Böbrek Hasarının Engellenmesinde Ellagic Asitin Koruyucu Etkilerinin İncelenmesi. Atatürk Üniversitesi Sağlık Bilimleri Enstitüsü, Doktora Tezi, 66s, Erzurum.

[31] Gao D., Wang H., Xu Y., Zheng D., Zhang Q., Li W. 2019. Protective Effect of Astaxanthin Against Contrast-Induced Acute Kidney Injury via SIRT1-p53 Pathway in Rats. International Urology and Nephrology, 51 (2): 351-358.

[32] Wang X., Zhao H., Shao Y., Wang P., Wei Y., Zhang W., Zhang Z. 2014. Nephroprotective Effect of Astaxanthin Against Trivalent Inorganic Arsenic-Induced Renal Injury in Wistar Rrats. Nutrition Research and Practice, 8 (1): 46-53.

[33] Kasai H., Nishimura S. 1993. Formation of 8-hydroxyguanine by Oxidative DNA Damage, its Repairandits Mutagenic Effects. In de Obe,G. (ed.) Advances in Mutagenesis Research. Springer-Verlag, Berlin, Germany, 4: 31-45.

[34] Umemura T., Sai K., Takagi A., Hasegawa R., Kurokawa Y. 1990. Formation of 8 hydroxydeoxyguaosine (8-OH-dG) in Rat Kidney DNA After Intraperitoneal Administration of Ferric Nitrilotriacetate (Fe-NTA). Carcinogenesis, 11: 345-347.

[35] Cheng K.C., Cahill D.S., Kasai H., Nishimura S., Loeb L.A. 1992. 8-Hydroxyguanine, an Abundant form of Oxidative DNA Damage, Causes $\mathrm{G} \rightarrow \mathrm{T}$ and $\mathrm{A} \rightarrow \mathrm{C}$ Substitutions. Journal of Biological Chemistry, 267: 166-172. 